\title{
The use of Digital Communications Tools by Latvian Environmental NGOs
}

\author{
Denis Vasiliev \\ Department of Commerce \\ Turiba University \\ Riga, Latvia \\ denisksil@gmail.com
}

\begin{abstract}
Successful nature conservation requires engagement of diverse groups of stakeholders. Attracting attention of general public and engagement of local communities that underpin sustainable development are between the most important aspects of effective communications by environmental non-governmental organizations (ENGOs). In the modern world digital tools provide unprecedented opportunities for broadening reach of ENGO communications. In Latvia, many organizations including ENGOs use digital tools as a part of their communications mix. However, it is important to understand to what extent the power of digital strategies is utilised by these organisations. For this purpose, analysis of Latvian ENGO digital strategies was undertaken. The analysis involved evaluation of digital usage by top Latvian ENGOs in comparison to application of online communications tools by similar organizations in Western Europe and in the USA. It was found that while Latvian ENGOs actively use digital communications tools, in comparison with western organizations a range of approaches that make online strategies effective is still underutilised. This may generally reduce reach of the communications and their public appeal. Ultimately, underuse of opportunities provided by digital communication tools may weaken effectiveness of nature conservation at a regional scale. Thus, it is suggested to enhance digital communications taking an example from Western ENGOS by introducing more educational and engaging content in a variety of formats, ranging from audio to video materials. Detailed recommendations based on findings of present review are provided.
\end{abstract}

Keywords - nature conservation, environmental governance, adaptive management, publicity strategies.

\section{INTRODUCTION}

The recent UN Global Biodiversity Outlook [1] has revealed that the World fails to protect biodiversity. The report suggests that majority of famous Aichi Biodiversity Targets [2] have not been achieved, including the Target 1
- "Increasing awareness of biodiversity". This target is particularly important for ENGOs, because biodiversity awareness building is among key tasks of such organizations. Moreover, success of conservation interventions undertaken by ENGOs often depends on collaboration with multiple stakeholder groups and public engagement, which is a part of effective adaptive management [3]. In the modern world most effective communication methods are based on application of digital tools [4]. Social media and other digital tools, such as websites and blogs tend to be not only much more cost effective than traditional off-line communication methods but also often more influential [5]. Moreover, it was found that digital communications maximise effectiveness of offline communications, when used together [6]. It is therefore important to understand to what extent ENGOs harness opportunities of digital communications.

However, evaluation of digital communication strategies in non-for-profit sector is much less straightforward than in commercial sector. In business, effectiveness of digital marketing communications is usually evaluated based on its contribution to company turnover and/or profits, using metrics such as Return on Investment (ROI) or lead generation. While such approach to evaluation of digital communication strategies is relatively straightforward, it is unapplicable to activities undertaken by ENGOs, because the ultimate goal of these organizations is not to generate sales and profits, but to increase awareness of biodiversity issues and ensure stakeholder engagement in nature conservation [7]. Therefore, aspects important for digital communications by ENGOs may include range of digital tools deployed, quality and diversity of the content, frequency of communications. However, to evaluate these parameters it is essential to deploy benchmarking approaches, comparing different NGOs. In this study, I decided to compare digital communications deployed by prominent 
Latvian ENGOs with similar organizations in Western European countries and in the USA.

Latvia has is between the leading counties in Europe in terms of internet speed and penetration [8, 9], outperforming even highly developed European counties, such as France, Germany, or the UK. This creates an ideal environment for ENGOs to use digital communications tools for engagement with diverse stakeholder groups. Generally, Latvian ENGOs are well known for successful management of communications campaigns influencing policymakers. For instance, thanks to famous communications activities of ENGOs Latvia currently is GMO free country [10]. These campaigns however, used a range of off-line and online tools with heavy emphasis on outdoor media. At the same time, Western European and American ENGOs have demonstrated extremely successful usage of digital tools. For instance, British ENGO "Buglife", has managed to implement national scale landscape connectivity network for pollinators called B-Lines mainly through engaging multiple stakeholder groups and general public using digital communications [11]. Thus, it is important to understand whether there is a space for further enhancement of communications strategies through the use of digital tools for Latvian ENGOs following examples of western colleagues. The aim of present study is to reveal the areas of potential enhancement of digital communications for Latvian ENGOs through comparing their strategies with the ones used in the Western European Countries - the UK, Germany, Ireland, and in the USA.

\section{MATERIALS AND METHODS}

In this study three prominent Latvian ENGOs: "Latvijas Zemes Draugi" ("Latvian Friends of Earth") [12], "Latvijas Dabas Fonds" ("The Latvian Fund for Nature”) [13] and "Vides aizsardzibas klubs" ("Latvian nature conservation club") [14]. These organizations were selected from the list provided by LETA media agency in Latvia, that provided ranking of the most significant nature conservation organizations in Latvia [15]. From this list only non-governmental, non-for-profit organizations were selected. In order to compare selected Latvian ENGOs similar organizations were selected from three Western European countries (the UK, Ireland and Germany) as well as from the USA, using Google search for top ENGOs in each country. One of such organizations was selected from each country: "Green Alliance" from the UK [16], "Friends of the Irish Environment" from Ireland [17], "Bund" from Germany [18] and "The Nature Conservancy" [19] from the USA. Websites and social media pages of the selected organizations from Latvia and from Western Europe and the USA were analysed using Excel spreadsheet with the following columns: name of the ENGO, country of origin, presence on social media platforms, local vs global appeal, content diversity, frequency of content publication, content quality. It was decided not to compare number of followers on social media platforms of the ENGOs, because of significant differences in population sizes of the selected countries and global appeal of some organizations. Digital strategies used by each organization were compared and evaluated. Evaluation criteria used for the analysis of ENGO websites included: website design clarity, whether the website is static or dynamic, whether it is translated to foreign languages, thereby having global appeal, whether the website has a blog and if yes whether this blog is regularly updated. For evaluation of ENGO performance at social media networks the following criteria were used: number of social media platforms at which each ENGO is present, frequency and number of posts, number of followers, type and quality of content shared at each platform, considering whether the content is dominated by text or includes photographic, audio, or video materials. Content quality as evaluated based on its nature - text, images or videos, as well as the quality of each content type, e.g. how professionally are photographic materials made, or how engaging is the content of video materials. Number of followers on social media networks was also considered, when evaluating content quality, based on an assumption that the higher content quality is the more followers will be attracted by the content.

\section{RESULTS}

Results of present study suggest that Latvian actively use ENGOs digital tools, including webpages and a broad range of social media platforms. The Website of "The Latvian Fund for Nature” has translation to English, the other two ENGOs have their websites and social media pages only in Latvian. All three selected organizations have clear, well developed webpages with a blog, which tends to be regularly updated. Furthermore, these ENGOs have Facebook landing pages, where they upload posts several times a week. Both "The Latvian Fund for Nature" and "Latvian nature conservation club" maintain pages at the popular local social media platform Draugiem.lv. In addition to that "The Latvian Fund for Nature" is present on Twitter, Instagram, LinkedIn and Vimeo, and uses RSS. However, Instagram, LinkedIn and Vimeo pages are not actively maintained with very small number of posts (12 posts on Instagram, 5 on LinkedIn and just 4 on Vimeo).

All three selected Latvian ENGOs have YouTube channels. However, it is important to note, that they have relatively small number of videos on YouTube channels, with "The Latvian Fund for Nature" having 95 videos, "The Latvian Friends of Earth" having 8 videos and "Latvian nature conservation club" - just 4 videos. Videos range from less than 2-minute short ones up to 5 hours long, with different type of content, ranging from interviews and expert opinions to documental films on nature and records of events. A very interesting feature on the "The Latvian Fund for Nature" YouTube channel are live translations from bird nests. This channel has more than 18000 subscribers and, as could be concluded from the live chat, this audience includes foreign viewers.

All foreign ENGOs considered in present study had robust websites with a blog and presence on social media. 
Websites of the organizations tended to be static, except for "The Nature Conservancy" website, which is dynamic and has very high-quality design. It is also important to note, that German ENGO "Bund" has very high quality of website design, too. Interestingly, all websites of the ENGOs considered in this study are only in one language - with "Bund" having a website in German and all other ENGOs - in English. Still, as clearly from the website content "The Nature Conservancy" has global appeal, unlike other ENGOs that focus mainly on local environmental issues.

Considering social media presence, all ENGOs have YouTube channels and Facebook pages. In addition, the ENGOs are present on photo sharing social networks, with "Green Alliance" present on Flickr and all other ENGOs having Instagram pages. Twitter tends to be used by "Green Alliance", "Bund” and "The Nature Conservancy”, but not by "Friends of the Irish Environment". Interestingly, the British "Green Alliance" and the American "The Nature Conservancy" are also represented at LinkedIn, while other ENGOs do not use this platform. "Green Alliance" also uses less popular social media platform - Wakelet. Interestingly, this organization also has its own podcast. RSS is used only by "Green Alliance" and "Friends of the Irish Environment". All foreign ENGOs explored in this study regularly post on Facebook (several times a week). Those ENGOs that have Twitter pages also update them regularly. Other social media channels tend to be maintained less intensively. Nevertheless, "The Nature Conservancy" and "Bund” very actively maintain YouTube channel with the former uploading videos weekly and the latter - monthly. At the same time "Green Alliance” generates monthly podcasts.

Quality and diversity of audio visual content posted by foreign ENGOs is generally very high. German ENGO "Bund" and American ENGO "The Nature Conservancy" produce a broad range of video content, including translation using live-cameras, engaging workshops, large scale migrations of birds and animals, educational content - explanations of ecological problems, case studies, episodes from live of indigenous people, interviews, community events etc. Audio content produced by the UK ENGO "Green Alliance", also excites with its diversity as it includes educational podcasts, podcasts considering policy issues, interviews, event records, discussions of environmental justice etc. Interestingly video materials were predominantly short, not exceeding $10 \mathrm{~min}$. Audio podcasts tended to be about half an hour long. It is also important to note that photos shared by foreign ENGOs on Instagram and Flickr are of a very high quality, too.

\section{DisCUSSION}

As follows from findings of the present study suggest that Latvian ENGOs actively use digital communications tools. However, comparison with leading foreign EBGOs has revealed that there is a scope for further development in this area. One really important area for improvement is the use of high-quality diverse video, photographical and audio content. Indeed, foreign ENGOs have substantial representation at such social media platforms as YouTube, Instagram and Flickr, and even use audio podcasts. Although Latvian ENGOs are represented at some of these platforms, quantity and diversity of the content tends to be relatively limited. This is an important issue, that may reduce effectiveness of digital communications. Recent scientific studies suggest that video and audio content, as well as images tend to be particularly effective in engaging target audiences and influencing their behaviour [20]. In addition to that, diversity of communications tools and the content itself tends to increase engagement with the target audiences and attract attention of a broader range of stakeholders with variety of interests, tastes, and preferences [21]. As follows from the results of the present study foreign ENGOs use a broad range of video or audio content, that has a great potential to be of interest to different social groups. For instance, "The Nature Conservancy" YouTube channel is full of high-quality video content that demonstrates aspects of animal life, educates people about most pressing environmental problems, tells stories about lives of indigenous people and teaches different useful skills, such as design etc. Positive effect from adding content diversity was also observed at "The Latvian Fund for Nature" YouTube channel, where the ENGO included live translations from bird nests. The page has a huge number of followers and attracts not only local but also foreign audiences. It is therefore recommended for Latvian ENGOs to produce more videos, images and, perhaps, audio content, with greater variety of topics. Clearly, producing high quality video and photographical content requires substantial financial investment and skills, which may not be available to ENGOs. However, in order to address this issue it is possible to harness European funds that are intended to building and increasing NGO capacity or other funding sources, that could be used for acquiring high quality equipment and paying for work invested in producing the content. Still, employing skilful employees on a permanent basis may be problematic for ENGOs with limited budgets, thus it is worth considering outsourcing production of the audio-visual content to professional organizations or engaging with volunteers [22].

Another area of potential need for further development in digital communications of Latvian ENGOs is consistency and frequency of the communications activities on social media. Although, all Latvian ENGOs explored in present study regularly update Facebook pages, activity on other social media platforms seems to be less regular and consistent in comparison with western ENGOs, which tend to produce regular posts across channels. It is well established, that communication frequency strongly affects its effectiveness [23]. Understandably, regularly producing and posting highquality content is a highly labour intensive task. However, it is worth the effort, as engaged stakeholders are likely to 
become supportive of the organization's values, thereby contributing to nature conservation [24]. The problem of lack of human resources may be resolved either through attracting additional funding or through collaboration with other stakeholders. As was mentioned earlier, ENGOs may attract volunteers. Another possible solution could be to establish collaboration with educational organisations, that could engage their students into ENGO communication activities.

One more important issue that requires attention is the broadness of appeal of ENGO communications. Interaction only with local environmentally conscious people may not be sufficient for mobilization of a broader society and implementation of effective adaptive management [25]. As was already discussed increasing variety of the content may increase broadness of organization`s appeal. In addition to that using content translation, may attract international audiences to support ENGOs. Interestingly, however, all ENGOs considered in the present study, both Latvian and foreign, had their websites and social media pages in just one language. Still, American and British ENGOs use English language in their digital communications, allowing them to secure international appeal without translating the content. For instance, American ENGO "The Nature Conservancy" is well known for its global activity. Results of present study revealed that Latvian ENGO ("The Latvian Fund for Nature" is already engaging with international audiences, by placing interesting content on its YouTube channel. However, translating content on the websites and social media platforms in English could broaden international appeal, potentially benefiting Latvian ENGOs.

\section{CONCLUSIONS}

The aim of present study was to reveal the areas of potential enhancement of digital communications for Latvian ENGOs by comparing their strategies with the ones used by foreign organizations. It was found that Latvian ENGOs in general are active users of digital media, however, there are still areas that need to be addressed in order to increase communications effectiveness. First of all, Latvian ENGOs need to use more video content and images and regularly post them on such popular social media platforms as YouTube and Instagram. This could substantially increase effectiveness of digital communications strategies. It is also important to note that increasing diversity of the content most likely will increase appeal of the communications facilitating public engagement in nature conservation activities. Secondly, frequency of content posting on social media platforms used by Latvian ENGOs needs to be increased, making it consistent across channels. Finally, broadness of the communications appeal could be magnified through translation of the content into foreign languages. All these improvements may be operationalised through harnessing European funds and other sources of funding, as well as through collaboration with other organizations and stakeholder groups.

\section{REFERENCES}

[1] Secretariat of the Convention on Biological Diversity. Global Biodiversity Outlook 5. Montreal, the United Nations, 2020.

[2] Aichi Biodiversity Targets [Online]. Available: https://www.cbd.int/sp/targets/ [Accessed: Feb. 10, 2021]

[3] M. Kaplan-Hallam and N.J. Bennett, "Adaptive social impact management for conservation and environmental management”, Conservation Biology, vol. 32(2), pp. 304-314 Jul. 2017, DOI: 10.1111/cobi.12985.

[4] S. Pavelle and C. Wilkinson, "Into the Digital Wild: Utilizing Twitter, Instagram, You Tube, and Facebook for Effective Science and Environmental Communication”. Frontiers in Communication, vol. 5(575122), Oct. 2020, DOI: 10.3389/fcomm.2020.575122.

[5] A. Lieberman and J. Schroeder "Two social lives: How differences between online and offline interaction influence social outcomes", Current Opinion in Psychology, vol. 31, pp. 16-21, Feb. 2020 , DOI: 10.1016/j.copsyc.2019.06.022

[6] Q. Shi, C. Wang, J. Chen, Y. Feng, C. Chen, "Location driven influence maximization: Online spread via offline deployment”, Knowledge-Based Systems, vol. 166, pp. 30-41, Feb. 2019, DOI: 10.1016/j.knosys.2018.12.003.

[7] P. Pacheco-Vega and A. Murdie, "When do environmental NGOs work? A test of the conditional effectiveness of environmental advocacy”, Environmental Policies, vol. 30(1-2), pp. 180-201, DOI: 10.1080/09644016.2020.1785261.

[8] Factmetrics, “Average Internet Speeds By Country”. [Online]. Available: https://www.fastmetrics.com/internet-connectionspeed-by-country.php\#top-10-worldwide [Accessed: Feb. 17, 2021].

[9] Tefficient, "USA, Latvia and Finland combine: High mobile data usage with fast growth". [Online]. Available: http://media.tefficient.com/2016/06/tefficient-industry-analysis-32016-mobile-data-usage-and-pricing-FY-2015-final2.pdf [Accessed: Feb. 18, 2021].

[10] GMO free Europe, “Latvia”. [Online]. Available: https://www.gmo-free-regions.org/gmo-free-regions/latvia.html [Accessed Feb. 12, 2021].

[11] Buglife, "B-Lines". [online]. Available: https://www.buglife.org.uk/our-work/b-lines/ [Accessed Feb 14, 2021].

[12] Latvijas Zemes Draugi (in Latvian). [Online]. Available: http://www.zemesdraugi.lv/ [Accessed Feb. 20, 2021]

[13] Latvijas Dabas Fonds (in Latvian). [Online]. Available: https://www.ldf.lv/ [Accessed Feb. 16, 2021]

[14] Vides aizsardzibas klubs (in Latvian). [Online]. Available: http://www.vak.lv/ [Accessed Feb 15, 2021].

[15] Latvijas Zala Josta (in Latvia). [Online]. Available: http://www.zalajosta.lv/lv/biedriba-latvijas-zala-josta-viena-nolielakajam-vides-aizsardzibas-organizacijam-latvija [Accepted Feb. 20, 2021]

[16] Green Alliance. [Online]. Available: https://green-alliance.org.uk/ [Accessed Feb. 19, 2021].

[17] Friends of the Irish Environment. [Online]. Available: https://www.friendsoftheirishenvironment.org/ [Accessed Feb. 20, 2021].

[18] Bund (in German). [Onlie]. Avaiable: https://www.bund.net/ [Accessed Feb. 22, 2021]

[19] The Nature Conservacy. [Online]. Available: https://www.nature.org/en-us/ \{Accessed Feb: 22, 2021]

[20] D. Grewala, D. Herhausenb, S. Ludwigc anf F.V. Ordenesd, “The future of digital communication research: Considering dynamics and multimodality”, Journal of Retailing, 18 Feb. 2021, [Online serial].

Available: https://www.sciencedirect.com/science/article/pii/S002243592100 $\underline{0075}$ [Accessed Accessed Feb. 2, 2021]

[21] R. Dolan, J. Conduit, C. Frethey-Bentham, J. Fahy and S. Goodman, "Social media engagement behavior: A framework for 
Environment. Technology. Resources. Rezekne, Latvia Proceedings of the $13^{\text {th }}$ International Scientific and Practical Conference. Volume 1, 250-254

engaging customers through social media content”, European Journal of Marketing, vol.53(10), pp. 2213-2243, Oct. 2019, DOI: 10.1108/EJM-03-2017-0182.

[22] M. Kumaran, "Organizational Capacity Building and Strategic Growth for Environmental NGOs: A Primer", WEIS (World Environment and Island Studies), vol. 8(1), pp. 11-21, Mar. 2018.

[23] C. Fill, "Essentially a Matter of Consistency: Integrated Marketing Communications”, The Marketing Review, vol. 1, pp. 409-425, Jul. 2001.
[24] F. Miriam, L.S.G. Piccolo, D. Maynard, M. Wippoo, C. Meili, and H. Alani, "Talking Climate Change via Social Media: Communication, Engagement and Behaviour”. In: WebSci '16 Proceedings of the 8th ACM Conference on Web Science, ACM, New York, USA, pp. 85-94, May 2016, DOI: 10.1145/2908131.2908167.

[25] H. Murphy-Gregory, “Governance via persuasion: environmental NGOs and the social licence to operate”, Environmental Policies, vol. 27(2), pp. 320-340, Sep. 2017, DOI: 10.1080/09644016.2017.1373429. 